\title{
Towards understanding corrosion initiation in concrete - Influence of local electrochemical properties of reinforcing steel
}

\author{
Lucas Michel $^{1 *}$, and Ueli Angst ${ }^{1}$ \\ ${ }^{1}$ ETH Zürich, Institute for Building Materials (IfB), ETH Hönggerberg, CH-8093 Zürich, Switzerland
}

\begin{abstract}
The ageing of reinforced concrete (RC) structures in the industrialized countries increases the probability of durability issues. The mechanism of chloride-induced corrosion, the most common deterioration process in RC structures, is still not well understood. Improvement in the understanding of localized corrosion initiation is crucially required to allow for cost efficient and durable maintenance of the existing infrastructures and for service life design of new structures. This study reports results from localized electrochemical characterization of reinforcing steel surfaces taken with a local sensor positioned at different locations on the rebars. This permitted "mapping" the local Open Circuit Potentials for different rebars with different surface conditions. Moreover, local cyclic voltammetries on selected spots were also carried out. Subsequently, the samples were exposed to a chloride solution to provoke corrosion initiation. The corrosion initiation sites from visual inspection were correlated with the local electrochemical characterization. Results show a clear difference depending on the surface condition. Furthermore, for non-rusted surfaces, a spatial distribution of the local electrochemical behaviors seems to follow a pattern depending on the geometry of the steel bar and influencing the location of corrosion initiation.
\end{abstract}

\section{Introduction}

In industrialized countries, most of the infrastructures were built at the beginning of the second half of last century [1]. A large fraction of these infrastructures bridges, tunnels, dams, building, etc. - are built with reinforced concrete, which is the most used manmade material in the world $[2,3]$. The frequency of durability issues increases with the ageing of structures and most of them are approaching the end or are already beyond the design service life.

The majority of durability issues in reinforced concrete structures are caused by corrosion of the reinforcing steel $[4,5]$. One mechanism leading to corrosion in concrete is governed by the presence of chloride ions at the steel surface. The influence of chloride on corrosion in concrete has been studied since the 60 's $[6,7,8]$. In these publications, a relation was established between the chloride concentration in concrete and the initiation of corrosion. Over the years, this concept received much attention, mainly because of the simplicity to measure, model, and control chloride concentrations in concrete.

Since these pioneering studies, substantial efforts have been made to find the so-called "critical chloride content" $\left(C_{\text {crit }}\right)$, that is the threshold chloride for corrosion initiation. A large amount of papers has been published presenting results from laboratory studies and from practical experience, as reviewed in detail in $[9,10]$. The literature results scatter widely, that is, $C_{\text {crit }}$ from 0.1 to $8.4 \%$ chloride by weight of cement, which leads to significant uncertainties in predictive modeling (service life design) and in maintenance planning (condition assessment). This large scatter can be seen as a result of the different methods used, but it may also simply arise from the (theoretical) nonexistence of a unique $C_{\text {crit }}$.

This is because of the many factors known to influence $C_{\text {crit }}$, most of which are related to the steelconcrete interface (SCI) [11-12]. For example, irregularities related to the concrete such as macroscopic voids [13], cracks, presence of aggregates, etc. may influence corrosion initiation. This is addressed in another contribution to this conference [14].

In this work, we propose to study spatial variations of the electrochemical behavior at the metal surface in order to characterize the distribution of local electrochemical properties. Many corrosion studies are carried out with electrochemical techniques, that generally allow for a fast characterization of several properties of a system metal/electrolyte [15-17]. Generally, these electrochemical characterizations are performed on full sample/electrode being immersed in the test electrolyte. This limits the possibility of obtaining information regarding spatial variation in electrochemical behavior. However, to elucidate why localized corrosion starts at some locations and not at others, we believe that characterizing the electrochemical properties at the local scale is important.

* Corresponding author: michellu@ifb.baug.ethz.ch 


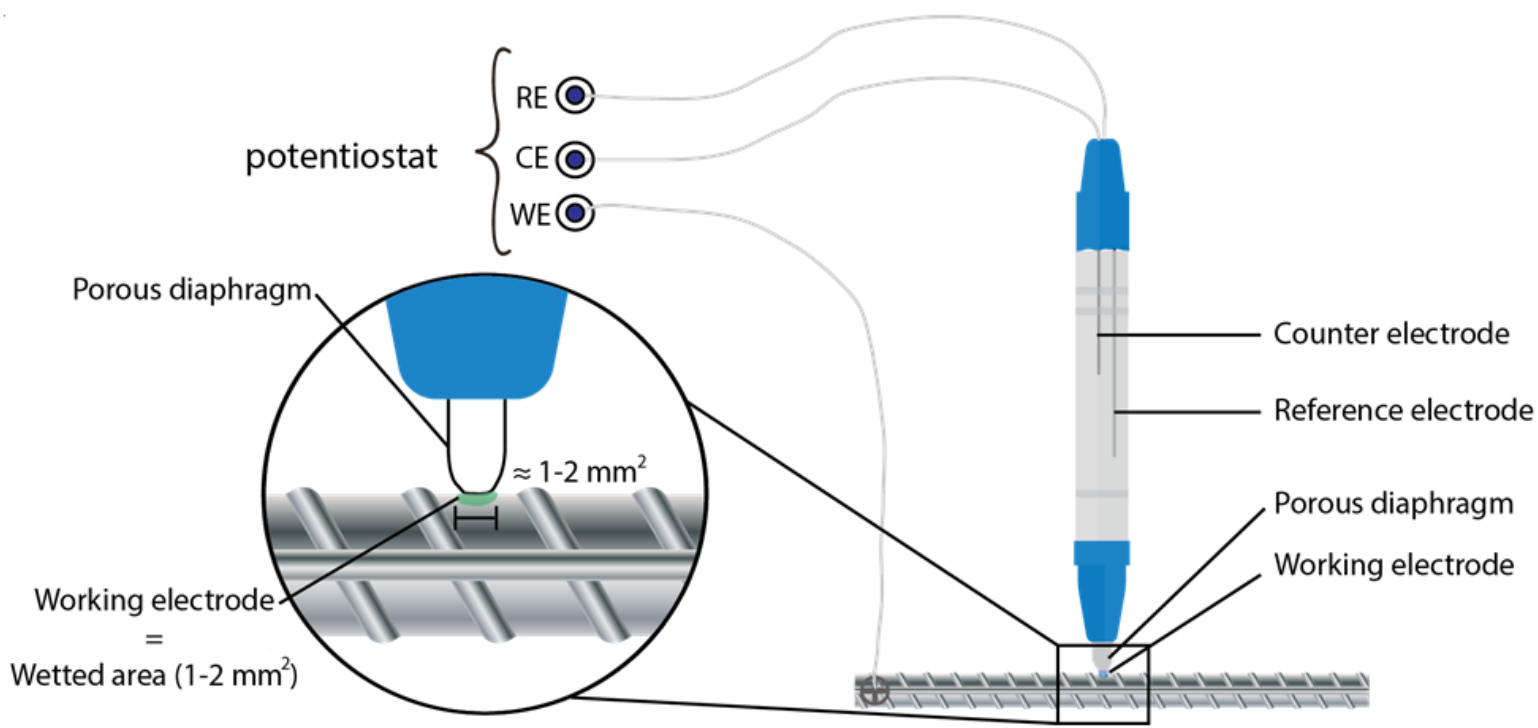

Fig. 1. Schema of the electrochemical sensor used for the local electrochemical measurements with an $\mathrm{Ag} / \mathrm{AgCl}$ reference electrode (RE), a Pt wire counter electrode (CE) integrated, with a close up showing the wetted area equivalent to the working electrode (WE) under test.

Different techniques for local electrochemical measurements are available, they were reviewed in $[18,19]$. One family of techniques is referred to as "scanning measuring techniques", because a small reference electrode is moved over the surface of a sample in an electrolyte to detect local potential differences. An inconvenience of these techniques is that they generally require flat (polished) surfaces. Moreover, mutual polarization of different zones of the sample surface during immersion may mask many important features. Another type of local electrochemical techniques, avoiding the latter limitation, is referred to as "point measuring techniques". In "microelectrochemistry", electrochemical experiments are performed on a well-controlled area, 1 to $1000 \mu \mathrm{m}$, with the help of a glass capillary filled with an electrolyte [20]. This method allows for a good control of the tested zone but requires some significant experimental effort and needs a relatively flat and smooth surface. This strongly limits the application to reinforcing steel, that has a non-flat surface with cylindrical shape and ribs.

In this work, we use a small portable electrochemical sensor, developed by the Swiss Society for Corrosion Protection [21]. This sensor with a pen-like shape can be filled with an electrolyte, contains a reference and a counter electrode. A polymer felt-like tip insures the electrolytic contact between the tested area and the reference/counter electrodes. The polymer tip size is around 1-2 $\mathrm{mm}^{2}$. The possibility to test non-flat, irregular surfaces and to avoid mutual polarization when immersing the "full sample" allows to characterize the local electrochemical properties of reinforcing steel.

\section{Experimental}

\subsection{Materials}

Three different types of plain carbon steel reinforcement bars, each $10 \mathrm{~cm}$ long with a diameter of $12 \mathrm{~mm}$ were used in this work. The three bars got a different degree of pre-existing rust. One bar was without rust (Fig. 3. a), one was slightly rusted (Fig. 3. b) and one was almost entirely covered with rust (Fig. 3. c).

Table 1. Designation, origin, degree of rust, and surface microstructure of tested materials.

\begin{tabular}{|c|l|l|l|}
\hline Designation & Origin & $\begin{array}{l}\text { Rust degree } \\
\text { on surface }\end{array}$ & $\begin{array}{l}\text { Surface } \\
\text { microstruct } \\
\text { ure }\end{array}$ \\
\hline Steel A & Spain & Low & $\begin{array}{l}\text { Tempered } \\
\text { Martensite }\end{array}$ \\
\hline Steel B & Sweden & Intermediate & $\begin{array}{l}\text { Tempered } \\
\text { Martensite }\end{array}$ \\
\hline Steel C & Denmark & High & $\begin{array}{l}\text { Tempered } \\
\text { Martensite }\end{array}$ \\
\hline
\end{tabular}

\subsection{Electrochemical sensor for local measurements}

All the potentials were measured with the help of the instrument "ec-pen" (Fig. 1.)[21]. This sensor consists of a cylindrical container of around $20 \mathrm{~mL}$, that can be filled with an electrolyte. Inside that electrolyte an $\mathrm{Ag} / \mathrm{AgCl}$ reference electrode and a platinum wire counter electrode are immersed. This set-up allows the classical three-electrode electrochemical measurements. At the end of the cylinder, a porous diaphragm tip 
insures the electrolytic connection between the area under test and the two electrodes of the sensor. The shape of this porous diaphragm defines the measurement area $\left(\approx 1-2 \mathrm{~mm}^{2}\right)$.

\subsubsection{Reference electrode potential of the sensor}

The reference potential of the $\mathrm{Ag} / \mathrm{AgCl}$ reference electrode is controlled by the chloride concentration of the test electrolyte. This means the electrolyte in the ecpen needs to contain some chloride ions to have a stable potential. The electrolyte used in all reported tests was a solution of $0.1 \mathrm{M}$ of $\mathrm{NaOH}(\mathrm{pH} 13)$ with $0.01 \mathrm{M}$ of $\mathrm{NaCl}$. All experiments were done at room temperature $\approx 20( \pm$ 2) ${ }^{\circ} \mathrm{C}$.

\subsection{Measurements}

\subsubsection{Open circuit potential}

The positioning of the ec-pen was done manually for each point on a defined grid with grid size of $2 \mathrm{~mm}$ in axial direction and $2 \mathrm{~mm}$ around the circumference of the steel bars. The Open Circuit Potential (OCP) was measured after $180 \mathrm{sec}$ of contact of the ec-pen with the surface (when typically a stable value was reached). OCP values were measured over a $4 \mathrm{~cm}$ long area of the steel bars.

\subsubsection{Cyclic voltammetry}

Cyclic voltammetry curves were measured at specified locations with the help of the ec-pen. The measurements started after $120 \mathrm{~s}$ of stabilization, the sweep went from $0 \mathrm{~V}$ to $-1.8 \mathrm{~V}$ and then up to $+1 \mathrm{~V}$ vs OCP. The sweep rate was $0.166 \mathrm{~V} / \mathrm{s}$. Two cycles were recorded and the measurement was stopped at $0 \mathrm{~V}$ vs OCP.

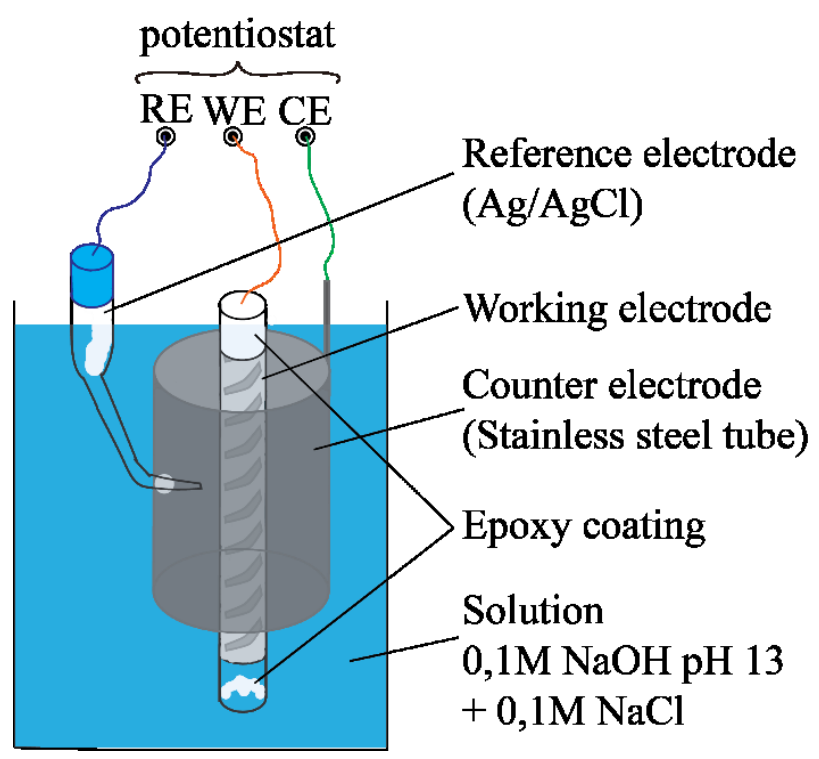

Fig. 1. Schema of corrosion test set-up.

\subsubsection{Corrosion test}

After characterization of the rebars as described above, the bar ends were coated with epoxy on both ends, and immersed in an alkaline test solution containing $0.1 \mathrm{M}$ $\mathrm{NaCl}$ (Fig. 2.). The samples were observed for 12 hours. When corrosion initiated (detected by a potential drop), the experiment was stopped. If corrosion did not initiate, the sample was anodically polarized with help of a counter electrode of cylindrical shape surrounding the bar. The polarization test started from $-50 \mathrm{mV}$ vs OCP until pitting at a scan rate of $1 \mathrm{mV} / \mathrm{s}$.

\section{Results}

\subsection{Local Open Circuit Potential}

The local OCP values measured on each steel bars can be plotted as "electrochemical behavior maps" of the steel surface (Fig. 3. d, e, and f). The more negative values appear black and the more positive values appear white on the electrochemical maps. For steel A (Fig. 3. a, and $d$ ) the distribution over the steel surface shows a clear tendency with more negative OCP values on the ribs areas and more positive OCP values located between the ribs. For steel B (Fig. 3. b, and e) the distribution of the OCP values seems to follow the same tendency with more negative values on ribs and more positive values between the ribs but it is less obvious than for steel A. For steel C (Fig. 3. c, and f) the distribution of the OCP values seems to be almost random without clear correlation with the geometry of the measurement area.

All the OCP values obtained are plotted on a cumulative probability distribution curve (fig. 4.) and the average value, the standard deviation, the minimum and the maximum for each steel bar are reported in table 2 . It can be noticed that the OCP values are becoming less negative when the degree of rust on the steel surface increases.

Indeed, both on the cumulative distribution curve and the average of OCP values show that steel A got a surface with more negative OCP values, with an average of $-363 \mathrm{mV}$ vs. $\mathrm{Ag} / \mathrm{AgCl}_{0.01 \mathrm{M}}$. OCP values measured on steel B shown a larger scatter and exhibit more positive values, with an average of $-307 \mathrm{mV}$ vs. $\mathrm{Ag} / \mathrm{AgCl}_{0.01 \mathrm{M}}$. The steel bar C OCP values are substantially more positive with an average of $-83 \mathrm{mV}$ vs. $\mathrm{Ag} / \mathrm{AgCl}_{0.01 \mathrm{M}}$.

\subsection{Cyclic Voltammetry}

After noticing that the measured OCP values could be significantly different depending on the location of measurement, cyclic voltammetry (CV) experiments were performed on selected spots at two different characteristic locations, namely on ribs and between ribs. For the steel B, CV were performed also on selected spots depending on their surface condition, that is, rusted and non-rusted surface. 
a)

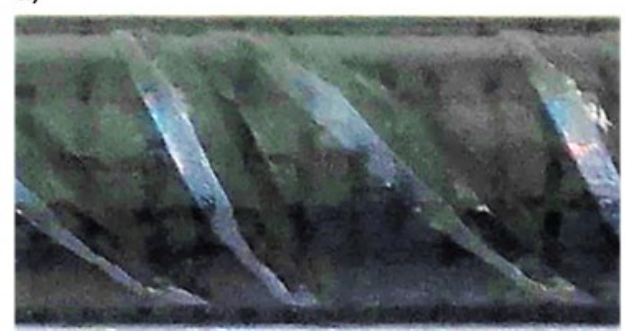

b)

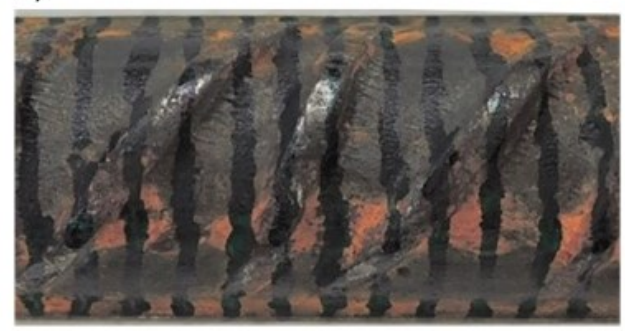

c)

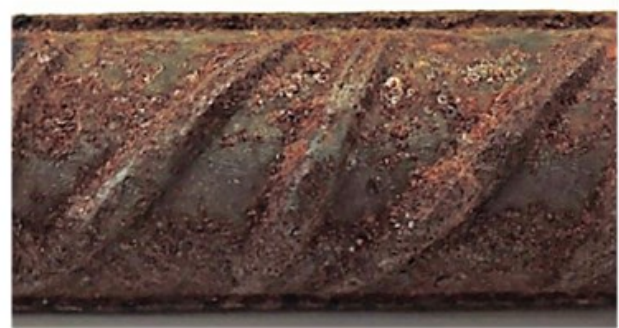

d)

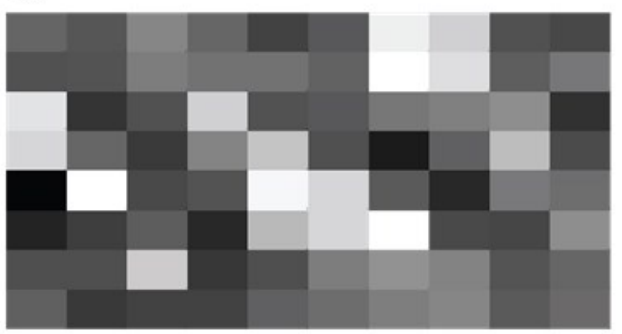

e)

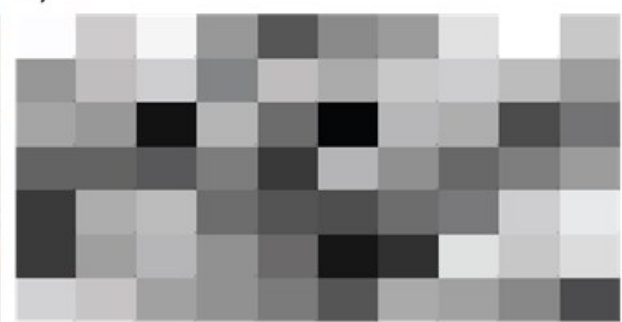

f)

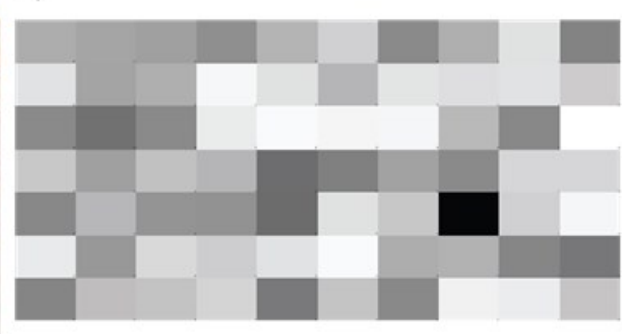

Legend

color OCP

$-0.499 \mathrm{mV}$

$-0.179 \mathrm{mV}$

Legend

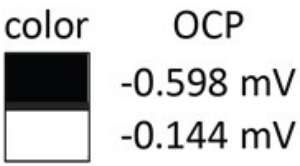

Legend

color OCP

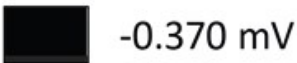

$0.073 \mathrm{mV}$

Fig. 3. Photographs of the different steel bars tested a) Steel A, b) steel B, and c) Steel C: and the correponding maps of the Open Circuit Potential values (vs $\mathrm{Ag} / \mathrm{AgCl}(0.01 \mathrm{M}$ ) measured on the same surfaces, d) steel $\mathrm{A}, \mathrm{e}$ ) steel $\mathrm{B}$, and f) steel C.

Some representative examples of cyclic voltammograms obtained for each steel on the different selected spots are visible in Fig. 5. The different voltammograms show a similar shape with only a clear peak located between $-0.8 \mathrm{~V}$ and $-0.2 \mathrm{~V}$ vs. $\mathrm{Ag} / \mathrm{AgCl}_{0.01 \mathrm{M}}$. In the voltammograms obtained on "clean" points without rust of steel A and B, shown in Fig. 5. a and Fig. 5. $\mathrm{b}$, the highest current intensity can be seen at a potential around $-0.7 \mathrm{~V}$ vs. $\mathrm{Ag} / \mathrm{AgCl}_{0.01 \mathrm{M}}$. Whereas, the highest current intensity for the voltammograms of rusted spots is shifted in a more positive direction, ca. $-0.5 \mathrm{~V}$ vs. $\mathrm{Ag} / \mathrm{AgCl}_{0.01 \mathrm{M}}$ for rusted spots of steel B (Fig. 5. b), and ca. $-0.2 \mathrm{~V}$ vs. $\mathrm{Ag} / \mathrm{AgCl}_{0.01 \mathrm{M}}$ for steel $\mathrm{C}$ (Fig.

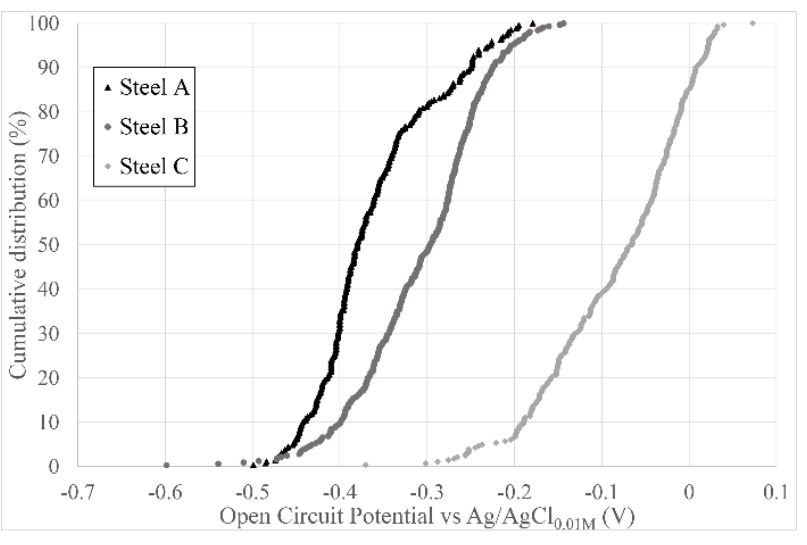

Fig. 4. Cumulative distribution curves of local OCP values measured with the ec-pen on each steel specimen. 5.c). The current intensities corresponding to these peaks, $\mathrm{I}_{\mathrm{p}}$, were in the range $11-25 \mu \mathrm{A}$ for rust-free spots,

Table 2. Local OCP averages, standard deviations, minimums and maximum values in $\mathrm{V}$ vs $\mathrm{Ag} / \mathrm{AgCl} \mathrm{l}_{0.01 \mathrm{M}}$, measured on each tested specimen.

\begin{tabular}{|l|l|l|l|l|}
\hline Specimen & $\begin{array}{l}\text { OCP } \\
\text { average }\end{array}$ & $\begin{array}{l}\text { OCP } \\
\text { standard } \\
\text { deviation }\end{array}$ & Min & Max \\
\hline Steel A & -0.363 & 0.068 & -0.499 & -0.179 \\
\hline Steel B & -0.307 & 0.072 & -0.598 & -0.144 \\
\hline Steel C & -0.083 & 0.080 & -0.370 & 0.073 \\
\hline
\end{tabular}

while in the presence of rust $I_{p}$ increased to $30-43 \mu \mathrm{A}$. The peak current intensities, $I_{p}$, and their corresponding potential, $\mathrm{E}_{\mathrm{Ip}}$, have been statistically analyzed to evaluate the distribution of the obtained values. Fig. 6. present the box plots of the measured $\mathrm{I}_{\mathrm{p}}$ and $\mathrm{E}_{\mathrm{Ip}}$ on the steel analyzed depending on the location and the surface state. Table 3 reports for each steel the average value of $\mathrm{I}_{\mathrm{p}}, \mathrm{E}_{\mathrm{Ip}}$, and their corresponding standard deviation.

There is a clear difference between the rusted and the clean spot measurements with both values $\mathrm{I}_{\mathrm{p}}$ and $\mathrm{E}_{\mathrm{Ip}}$. The current intensity at the peak $\mathrm{I}_{\mathrm{p}}$ appear to be much higher for the rusted points than the clean points, and the scatter of obtained values is also larger for the rusted points 


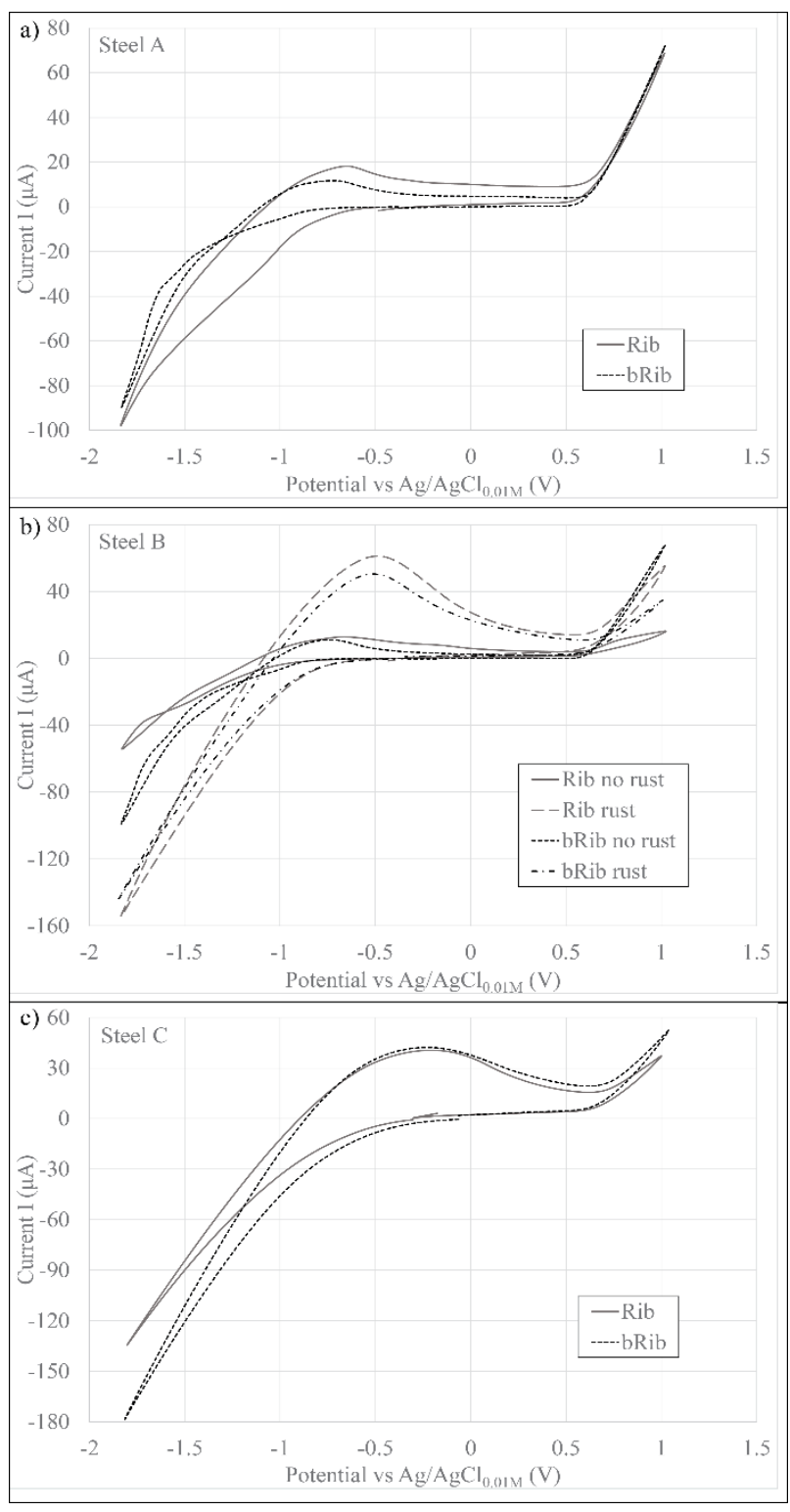

Fig. 5. Cyclic voltammograms for each type of selected spots. a) representative example for steel A for measurement performed on rib (Rib) and between ribs (bRib); b) representative example for steel B for measurement performed on rustfree areas, rib (Rib no rust) and between ribs (bRib no rust), and on rust areas, rib (Rib rust) and between ribs (bRib rust); c) representative example for steel $\mathrm{C}$ for measurements on rib (Rib) and between ribs (bRib).

compared to the clean points. The values of $\mathrm{E}_{\mathrm{Ip}}$ are also more widely distributed for rusted points than for the clean points.

\subsection{Corrosion initiation}

After the different local characterizations, the analyzed steels were subjected to a corrosion test until initiation of corrosion (Fig. 2). For steel B and C corrosion started during the immersion time and no polarization was necessary. For steel A, anodic polarization was needed to initiate corrosion. The main objective of this test was to provoke corrosion initiation in order to analyze the location of initiation and compare it to the electrochemical local characterization. Fig. 7. shows pictures of pitting locations on the different steel bars. On steel A and B (Fig. 7. a, and b) the pits were located mostly on the ribs, whereas on steel $\mathrm{C}$ (Fig. 7. c) corrosion pits were found between the ribs.

\section{Discussion}

\subsection{Origin of the local OCP variations}

The three steels analyzed present a different surface condition, with a different degree of rust present on their surface. This is reflected by clearly different values in their OCP averages and distributions (Fig. 4. and table 2 ). The values of the local OCP increase with the increase of rust degree. This finding is in agreement with a previous study [22].

On the clean steel A, there is a clear dependency of OCP on the location. OCP recorded at rib surfaces present more negative values than OCP measured on areas between ribs (Fig. 3. a). The presence of rust products on the surface seems to have a bigger influence on OCP values than the location differences measured on clean steel bars. On the highly rusted steel $\mathrm{C}$ the OCP distribution appear to be more random without clear influence of location (rib vs. between ribs) (Fig. 3. c). Thus, the surface of the steel bar is homogenized by the presence of rust. The distribution of OCP values on steel B seems to be a mix of these two extreme cases (Fig. 3. b), with still a tendency to find more negative OCP on ribs but not as clear than on steel A.

The origin of the distribution on steel A may be explained by different factors. The surface of "asreceived" steel reinforcing bars is covered by the mill scale, a thick oxide layer of approx. 20-40 $\mu \mathrm{m}$ [23]. The characteristics (thickness, morphology, composition) of this mill scale layer may be different depending on its location, on the ribs or between them. Steel bar A present a martensitic surface layer, formed during the manufacturing process. This surface layer may also be different depending on its location on the rebar topography due to different heating times in the thermomechanical strengthening process (different surface stress, different grain distribution, etc.). Finally, also the shaping of the reinforcing steel (ribs) may have induced different degrees of lattice defects and metallurgical properties that affect the local electrochemical behavior. 

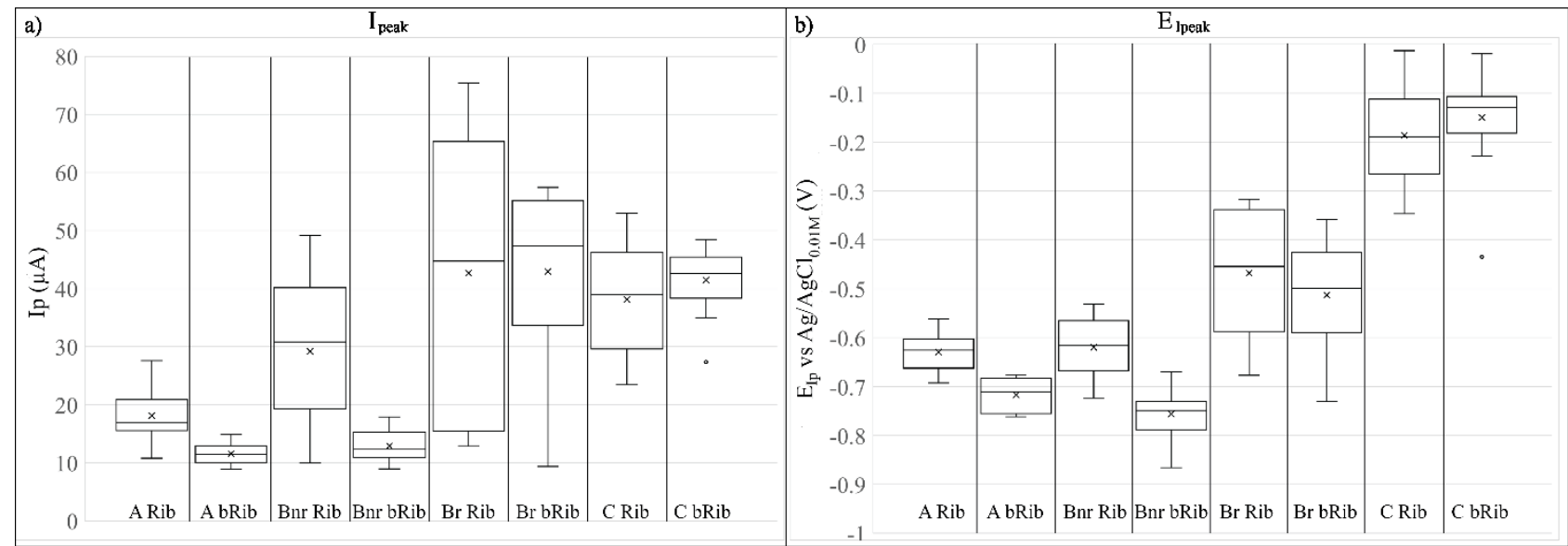

Fig. 6. Box plots of the higher current intensities measured during the first cycle of local cyclic voltammetry $I_{p}$, and the potential where $\mathrm{I}_{\mathrm{p}}$ is located $\mathrm{E}_{\mathrm{Ip}}$, for each selected spot. Measurement on steel A are labeled A rib and A bRib for spots on ribs and between ribs respectively. Measurements on steel B are labeled Bnr Rib and Bnr bRib for rust-free spots located on ribs and between ribs respectively, $\mathrm{Br} \mathrm{Rib}$ and $\mathrm{Br}$ bRib correspond to spots with rust located on ribs and between the ribs. Measurement on steel $\mathrm{C}$ are labeled $\mathrm{C}$ Rib and $\mathrm{C} b \mathrm{Rib}$, for spots on ribs and between the ribs respectively.

\subsection{Differences in obtained voltammograms}

The peak in current visible in the voltammograms of rust-free surfaces, located at around $-0.7 \mathrm{~V}$ vs. $\mathrm{Ag} / \mathrm{AgCl}_{0.01 \mathrm{M}}$ corresponds most likely to the oxidation of $\mathrm{Fe}^{2+}$ to $\mathrm{Fe}^{3+}$ [24]. In presence of rust on the spot of measurement, the peak current intensity $I_{p}$ is substantially higher and $\mathrm{E}_{\mathrm{Ip}}$ is shifted in anodic direction from ca. $-0.7 \mathrm{~V}$ to ca. $-0.5 \mathrm{~V}$ vs. $\mathrm{Ag} / \mathrm{AgCl}_{0.01 \mathrm{M}}$ for steel $\mathrm{B}$ and even to ca. $-0.17 \mathrm{~V}$ vs. $\mathrm{Ag} / \mathrm{AgCl}_{0.01 \mathrm{M}}$ for steel $\mathrm{C}$ (Fig. 5. And Fig 6.). These results are in agreement with [25].

Similar to the OCP variations, a rust-free surface seems to exhibit a significant difference in $I_{p}$ and $E_{I p}$ values depending on the point of measurement, on the ribs or between them. For rusted surfaces, on the other hand, the wider distribution of $\mathrm{I}_{\mathrm{p}}$ values measured on each type of selected spot and the relative closeness between them does not allow to determine the existence of any difference between locations of measurements. Highest $\mathrm{I}_{\mathrm{p}}$ values suggest a higher amount of $\mathrm{Fe}^{2+}$ (more rust), or a higher reactivity of the $\mathrm{Fe}^{2+}$ present on the surface, meaning a surface composition different or a different morphology (e.g. higher effective surface area). Like for the local OCP values, the results obtained by performing local cyclic voltammetries on selected spots show a clear difference between clean and highly rusted steel bars. Clean steels exhibit spatial variations depending on the geometry (ribs $\neq$ between ribs). The presence of rust modifies the local electrochemical behavior and homogenizes the differences depending on the location of measurements.

\subsection{Correlation between the local variations and initiation of corrosion?}

Based on the obtained results of corrosion initiation, rust seems to have a negative effect on the corrosion resistance. This result is in agreement with [26-29]. Indeed anodic polarization was necessary to initiate corrosion only for the clean steel A, whereas corrosion of the slightly rusted steel B and highly rusted steel C initiated without any polarization.

Table 3. $\mathrm{I}_{\mathrm{p}}$ averages, standard deviations in $\mu \mathrm{A}$, and $\mathrm{EIp}_{\mathrm{I}}$ averages, standard deviations in $\mathrm{V}$ vs $\mathrm{Ag} / \mathrm{AgCl}{ }_{0.01 \mathrm{M}}$ measured for each specific selected spots.

\begin{tabular}{cccccc}
\hline Specimen & location & $\mathrm{I}_{\mathrm{p}}$ average & $\begin{array}{c}\mathrm{I}_{\mathrm{p}} \text { standard } \\
\text { deviation }\end{array}$ & $\mathrm{E}_{\mathrm{Ip}}$ average & $\begin{array}{c}\mathrm{E}_{\mathrm{Ip}} \text { standard } \\
\text { deviation }\end{array}$ \\
\hline Steel A & $\begin{array}{c}\text { Ribs } \\
\text { bRibs }\end{array}$ & 18.1 & 4.13 & -0.630 & 0.036 \\
& Ribs non & 25.5 & 1.76 & -0.717 & 0.031 \\
\hline \multirow{2}{*}{ Steel B } & $\begin{array}{c}\text { rusted } \\
\text { bRibs non } \\
\text { rusted }\end{array}$ & 13.6 & 2.40 & -0.624 & 0.057 \\
& $\begin{array}{c}\text { Ribs rusted } \\
\text { bRibs rusted }\end{array}$ & 43.0 & 18.11 & -0.756 & 0.048 \\
& 29.1 & 19.25 & -0.468 & 0.124 \\
\hline Steel C & Ribs & 38.1 & 8.87 & -0.186 & 0.113 \\
& bRibs & 41.5 & 5.07 & -0.150 & 0.091 \\
& & & & & 0.088 \\
\hline
\end{tabular}


a) Steel $\mathrm{A}$

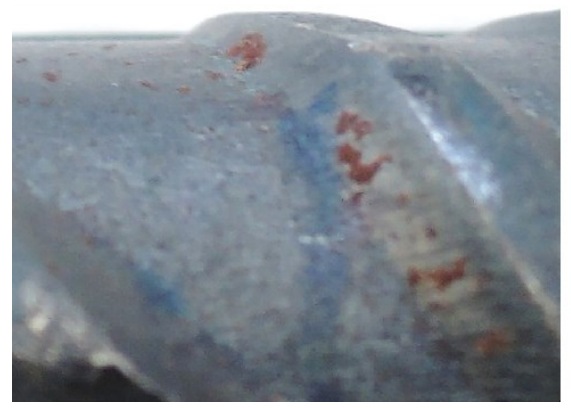

b) Steel B

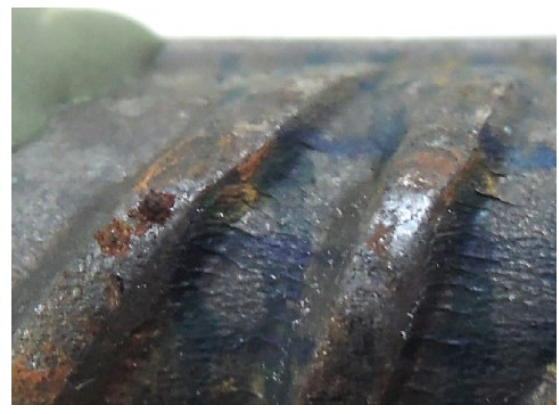

c) Steel C

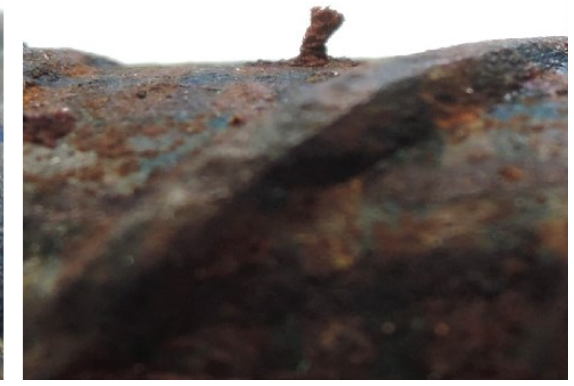

Fig. 7. Close up photographs of pitting corrosion initiation sites on each tested steel.

On clean steel A and slightly rusted steel $\mathrm{B}$, the pits were located on the ribs. A comparison of local electrochemical behaviors on steel A let us see that corrosion initiated at locations where OCP values are more negative and where $I_{p}$ obtained during cycling voltammetry is the highest. If this highest current intensity is caused by a highest reactivity of the $\mathrm{Fe}^{2+}$ it could be a part of the explanation for occurrence of pitting on those areas. On steel $\mathrm{C}$ where the high amount of rust seems to homogenize the local electrochemical behaviors through the surface, pits were found between the ribs. This could be explained by the highest area between the ribs compared to the area on the ribs. Therefore, the probability to find corrosion initiation sites is higher between the ribs than on the ribs. Steel B seems to have an intermediate behavior, with an initiation of corrosion following the behavior of highly rusted steel $\mathrm{C}$ and a location of corrosion initiation similar to clean steel A. Maybe the behaviors of the slightly rusted steels can be predicted by the ratio between clean and rusted areas.

Note that so far, only three bars were tested. While the numerous local measurements on these agree well with the topography and initial rust state of the rebars, more tests are needed to explain the location of corrosion initiation based on these tests.

\section{Conclusion}

Mapping of local Open Circuit Potential has been performed on steel surfaces with different surface conditions. Cyclic voltammetry has been performed on selected spots depending on their location and their surface condition. Results show different distributions depending on the general surface state of the steel. The presence of rust on the steel was found to modify and homogenize the local electrochemical behaviors. Results on rust-free steel surfaces suggest a different electrochemical behavior of areas between ribs and areas on ribs.

Some preliminary corrosion tests were performed and promising results were obtained, especially regarding correlations between the local electrochemical measurements and the locations of corrosion initiation on the steel surface free from rust.
The authors believe the study of spatial variation of electrochemical behaviors on steel surface can help to understand the pitting corrosion initiation in concrete. In order to collect more efficiently local data, an ongoing project at the Institute of Building Materials (IfB) at ETH Zurich aims at the robot-assisted automation of the measurement (in collaboration with the Institute for Lab Automation and Mechatronics (ILT) at Hochschule of Rapperswil).

\section{References}

1. NACE International, A NACE International white paper on "Corrosion Control Plan for Bridges". NACE International, Houston (2012)

2. R. J. Flatt, N. Roussel, C. R. Cheeseman, J. Eur. Ceram. Soc. 32, 2787-2798 (2012)

3. World Business Council for Sustainable Development, Cement Sustainability Initiative

4. Development of an holistic approach to ensure the durability of new concrete construction. British cement association, Crowthorne, (1997)

5. Fédération Internationale du Béton (fib) fib bulletin no. 59 Condition control and assessment of reinforced concrete structure exposed to corrosive environments. (2011)

6. D.A. Haussmann, Materials Protection, 6, 19-23 (1967)

7. W. Richartz, Zement-Kalk-Gips, 10, 447-456 (1969)

8. P. Vassie, Proc. Instn Civ. Engrs., Part 1, 76, 713723 (1984)

9. U. Angst, B. Elsener, C.K. Larsen, Ø. Vennesland, Cem. Concr. Res., 39, 1122-1138 (2009)

10. U. Angst, Ø. Vennesland, Critical chloride content in reinforced concrete - state of the art., Concrete Repair, Rehabilitation and Retrofitting II, M.G. Alexander et al., Editors. 2008 149, CRC Press/Balkema, The Netherland, Cape Town (SA) (2008)

11. U.M. Angst, B. Elsener, Sci. Adv., 3, 8 (2017)

12. U.M. Angst, M.R. Geiker, A. Michel \& Al., Mater. Struct., 50(2), 143 (2017)

13. T.A. Soylev, R. Francois, Cem. Concr. Res., 33, 1407-1415 (2003)

14. C. Boschmann Käthler, U.M. Angst, B. Elsener, Towards understanding corrosion initiation in 
concrete - influence of local concrete properties in the steel-concrete interfacial zone, in ICCRRR, $\mathrm{H}$. Beushausen, Editor. 2018, in preparation: Cape Town.

15. A.J. Bard, L.R. Faulkner, Electrochemical methods - Fundamentals and Applications, 2nd ed., J. Wiley \& Sons (2001)

16. R. Baboian, Corrosion test and Standards: Application and Interpretation, ASTM International (2005)

17. R. Varma, J.R. Selman, Techniques for Characterization of Electrodes and Electrochemical Processes, J. Wiley \& Sons (1991)

18. R. Leiva-Garcia, \& Al., Modern Electrochemical Methods in Nano, Surface and Corrosion Science, InTech, 239 (2014)

19. M.Y. Tan, R.W. Revie, Heterogeneous electrode processes and localized corrosion. Vol.13. J. Wiley \& Sons (2012)

20. T. Suter, H. Böhni, Electrochem. Acta, 42, 32753280 (1997)
21. M. Büchler, C.-H. Voûte, F. Stalder, Electrochemical Society Proceeding, 24, 436-441 (2002)

22. M. Stefanoni, U. Angst, B. Elsener, Corros. Sci., 98, 610-618 (2015)

23. P. Ghods, O.B. Isgor, G.A. McRae, J. Li, G.P. Gu, Corros. Sci., 53, 946-954 (2011)

24. E. Volpi, A. Olietti, M. Stefanoni, S.P. Trasatti, J. Electroanal. Chem., 736, 38-46 (2015)

25. U.M. Angst, and B. Elsener, Forecasting chlorideinduced reinforcement corrosion in concrete, in ICCRRR - Concrete Repair, Rehabilitation and Retrofitting IV, F. Dehn, et Al., Editors. 2015, CRC Press: Leipzig (D) (2015)

26. L. Li, A.A. Sagüés, Corrosion, 57, 19-28 (2001)

27. L.T., Mammoliti, L.C. Brown, C.M. Hansson, B.B Hope, Cem. Concr. Res., 26, 545-550 (1996)

28. M. Manera, Ø. Vennesland, L. Bertolini, Corros. Sci., 50, 554-560 (2008)

29. R.G. Pillai, D. Trejo, ACI Mater. J., 102, 103-109 (2005) 